\title{
Risk Factors for Cardiovascular Disease Among Active Adult US Scuba Divers
}

Peter Buzzacott, ${ }^{\mathrm{a}, \mathrm{b}^{*}}$ Charles Edelson, ${ }^{\mathrm{a}, \mathrm{c}}$ Caslyn M Bennett, ${ }^{\mathrm{a}}$ Petar J Denoble. ${ }^{\mathrm{a}}$

${ }^{a}$ Divers Alert Network, Durham, North Carolina, USA

${ }^{\mathrm{b}}$ School of Sports Science Exercise and Health, University of Western Australia, Crawley,

Western Australia, Australia

${ }^{c}$ New College of Florida, Sarasota, Florida, USA.

*Corresponding author

Peter Buzzacott

Divers Alert Network

6 West Colony Place

Durham, NC 27705

United States of America

Ph: +1 (919)-684-2948 ext 1627

E-mail: pbuzzacott@dan.org

This work was funded by Divers Alert Network.

The authors report no conflicts of interest.

This manuscript is submitted as a Short Report.

Unstructured abstract word count $=93$ words .

Main text contains 1000 words, one Table and 10 references. 


\begin{abstract}
Cardiovascular factors among uninjured active adult recreational scuba divers in the U.S. are described. Scuba diving as an activity was included in 2011, 2013 and 2015 Behavioral Risk Factor Surveillance System data. One-third of active U.S. scuba divers were aged $\geq 50$ years and/or reported prior high cholesterol, around half were overweight, more than half reported having smoked cigarettes, and 32\% reported hypertension or borderline hypertension. High cholesterol, hypertension, high body mass index and smoking status should all be addressed during routine diving fitness physician assessments, to reduce the risk of mortality while diving.
\end{abstract}

Abstract word count $=93$ words

Keywords: Surveillance, hypertension, body mass index, risk factors. 
Introduction Scuba diving is a popular recreational pursuit enjoyed by millions of U.S. divers (1). It is estimated around $1.1 \%$ of residents scuba dive each year. Annually, in the U.S. around 80 scuba divers die and 1,400 present at U.S. Emergency Departments (1). The mean age of U.S. recreational diving fatalities has increased steadily over the last 25 years $(2,3)$. Cardiovascular risk factors (CVRF) are now implicated in a large proportion of deaths and injuries among U.S. recreational divers (4). The aim of this study is to describe CVRF among active adult recreational scuba divers in the U.S.

Methods The Behavioral Risk Factor Surveillance System (BRFSS) is a telephone-based survey of noninstitutionalized adults in the U.S. and U.S. Territories (5-7). Every second year a survey module investigates patterns of physical activity and exercise. The pertinent BRFSS survey questions are:

- During the past month, other than your regular job, did you participate in any physical activities or exercises such as running, calisthenics, golf, gardening, or walking for exercise?

- What type of physical activity or exercise did you spend the most time doing during the past month?

- What other type of physical activity gave you the next most exercise during the past month?

Scuba diving as an activity was included in 2011, 2013 and 2015 surveys (5-7). BRFSS data are weighted using an iterative raking method, de-identified and made available through the Centers for Disease Control and Prevention, therefore the Institutional Review Board (IRB) of the Divers Alert Network ruled this study exempt from requiring approval (letter available on request). SAS version 9.4 was used for the analysis. Before combining the three years of data, annual weights were adjusted proportionally to each year's contribution to the combined dataset, as previously described (8). All data reported by this study are national estimates, generated by summing the adjusted annual weights (9). We believe this appropriate where:

- the sample is as small as it is for divers,

- the divers are distributed across the U.S.,

- the minimum cell size $\geq 50$

A comparison group of active participants with a ratio of three per diver (actual participants, not weighted estimates) was selected. This group were active in activities other than diving and were matched to the divers on survey year, age ( 5 year bin), sex and state of residence. Relative risks were calculated with exact confidence intervals, as recommended for small sample sizes (10).

Results Combined proportionally adjusted 2011, 2013 and 2015 BRFSS surveys gave a national estimate of $735,750,527$ persons. Of those, $497,733,757$ (68\%) were reportedly active in the previous month and $113,892(0.02 \%)$ indicated the activity they had been most, or next most, active in was scuba diving. The comparison group, matched on age, sex, and state of residence, equated to a national sample of 338,933 people who considered themselves to have been active during the previous month, mostly (and next mostly) in an activity that was not scuba diving.

Both age groups and sex variables contained $<50$ unweighted count in at least one cell (e.g. $<50$ female divers) therefore these distributions are not reported at the individual class level. Florida and California accounted for $34 \%$ of active divers. Median frequency scuba diving was once per week. Mean duration engaged in scuba diving was two hours. Mean Body Mass Index (BMI) among the divers was 26.1 (95\% $\mathrm{Cl} 25.5,26.7)$ and among the non-divers 27.3 (95\% Cl 26.8, 27.7, $\mathrm{p}<0.0001)$. Among the divers mean agesex estimated VO2max was $35.2 \mathrm{ml} .(\mathrm{kg} . \mathrm{min})^{-1}$ The great majority, $(>90 \%)$ reported no history of coronary heart disease, heart attack, stroke, asthma, any forms of cancer, kidney disease, diabetes or depressive disorders. The majority (78\%) of divers reported having some form of health care coverage. 
Prior diagnosis of high cholesterol (Table 1) was reported in $30 \%$ of divers and the control group, and around one-third of either group were aged 50 years or older. 
Table 1: Demography and cardiovascular risk factors of active US adult scuba divers and control group, 2011-2015

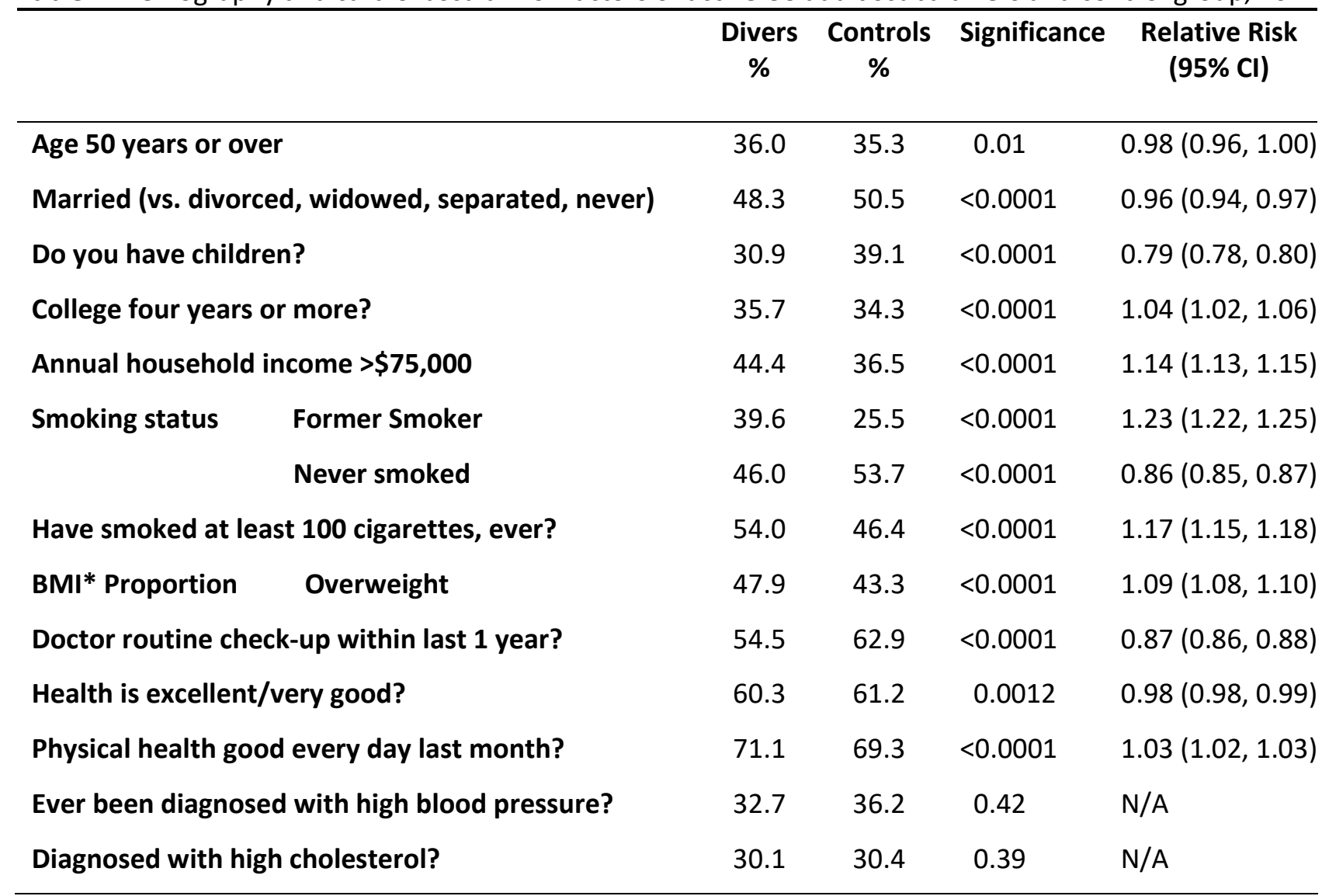

*Body Mass Index 
Discussion One third of active U.S. adult scuba divers in this BHFSS sample were $\geq 50$ years old. A greater proportion of divers had smoked at some point but, compared with the control group, a greater proportion had given up smoking. Divers were more frequently overweight but had lower mean BMI overall than the control group. There was no relative difference in hypertension or high cholesterol diagnoses, though around one third of divers reported either or both conditions.

Scuba diving is a geographically concentrated sport confined to locations with access to popular dive sites and, therefore, the BRFSS may not accurately reflect the true distribution of US active divers. Active divers were, however, distributed across 44 U.S. states and territories, with Florida and California accounting for $34 \%$ of all divers, which is also in keeping with U.S. recreational diving fatalities $(3,4)$. Diving activity in the U.S. peaks during summer and the survey was conducted throughout the year, which may also have affected the results. The comparison group may still have been scuba diving, but simply listed another activity as their main type of activity. It is unlikely any individual diver participated in this survey more than once.

The U.S. adult recreational diving community is a dynamic population. Prospective research with representative sampling is required to characterize active U.S. recreational divers. No previous study has attempted this and hitherto it was largely unknown what modifiable risk factors exist to prevent death or injury among active US scuba divers. Active adult U.S. scuba divers are often well educated, more than half earn $\geq \$ 75,000$ per year, and they are commonly married with children (Table 1). High cholesterol, hypertension, high BMI and smoking status should all be addressed during routine diving fitness physician assessments, to reduce the risk of mortality while diving.

\section{References}

1. Buzzacott P, Schiller D, Crain J, Denoble PJ. Epidemiology of morbidity and mortality in US and Canadian recreational scuba diving. Public Health. 2018;155:62-8.

2. Denoble PJ, Pollock NW, Vaithiyanathan P, Caruso JL, Dovenbarger JA, Vann RD. Scuba injury death rate among insured DAN members. Diving Hyperb Med. 2008;38:182-8.

3. Mease A, Buzzacott $P$, Denoble P. Appendix A: Thirty years of DAN injury surveillance. In: Buzzacott P, editor. DAN Annual Diving Report 2017 Edition: A Report on 2015 Diving Fatalities, Injuries, and Incidents. Durham (NC): Divers Alert Network; 2017.

4. Buzzacott P. Section 1: Diving Fatalities. In: Buzzacott P, editor. DAN Annual Diving Report 2017 Edition: A Report on 2015 Diving Fatalities, Injuries, and Incidents. Durham (NC): Divers Alert Network; 2017.

5. Behavioral Risk Factor Surveillance System 2011 summary data quality report (Version \#5). Atlanta (GA): Centers for Disease Control and Prevention; February 2013. https://www.cdc.gov/brfss/annual_data/2011/pdf/2011_summary_data_quality_report.pdf. Accessed May 14, 2018.

6. Behavioral Risk Factor Surveillance System 2013 summary data quality report. Atlanta (GA): Centers for Disease Control and Prevention; August 2014. https://www.cdc.gov/brfss/annual_data/2013/pdf/2013_dqr.pdf. Accessed May 14, 2018.

7. Behavioral Risk Factor Surveillance System 2015 summary data quality report. Atlanta (GA): Centers for Disease Control and Prevention; July 2015. https://www.cdc.gov/brfss/annual_data/2015/pdf/2015-sdqr.pdf. Accessed May 14, 2018.

8. Santorelli ML, Ekanayake RM, Wilkerson-Leconte L. Participation in a Diabetes Self-Management Class Among Adults With Diabetes, New Jersey 2013-2015. Prev Chronic Dis. 2017;14:E63. 
9. Iachan R, Pierannunzi C, Healey K, Greenlund KJ, Town M. National weighting of data from the Behavioral Risk Factor Surveillance System (BRFSS). BMC Med Res Methodol. 2016;16(1):155.

10. Andresen EM, Diehr PH, Luke DA. Public health surveillance of low-frequency populations. Annu Rev Public Health. 2004;25:25-52. 